\title{
Truthmaker commitments
}

\author{
Jonathan Schaffer
}

(C) Springer Science+Business Media B.V. 2008

\begin{abstract}
On the truthmaker view of ontological commitment [Heil (From an ontological point of view, 2003); Armstrong (Truth and truthmakers, 2004); Cameron (Philosophical Studies, 2008)], a theory is committed to the entities needed in the world for the theory to be made true. I argue that this view puts truthmaking to the wrong task. None of the leading accounts of truthmaking-via necessitation, supervenience, or grounding - can provide a viable measure of ontological commitment. But the grounding account does provide a needed constraint on what is fundamental. So I conclude that truthmaker commitments are not a rival to quantifier commitments, but a needed complement. The quantifier commitments are what a theory says exists, while the truthmaker commitments are what a theory says is fundamental.
\end{abstract}

Keywords Truthmaker · Commitment · Grounding · Fundamental

\section{Ontological commitments}

The ontological commitments of a theory are what the theory says exists. Thus consider the simply theory $T_{\text {yоu }}$ whose only sentence is:

\section{$T_{\text {you }}$ : You exist}

Evidently $T_{\text {you }}$ is committed to the existence of you. Anyone who believes $T_{\text {you }}$ is rationally required to believe in the existence of you. To believe $T_{\text {you }}$ but not confess to your existence is to be an ontological shirker.

On the orthodox quantifier view (Quine 1963), a theory is committed to what is needed by the domain for an apt regimentation of the theory to be true. Applied to

\footnotetext{
J. Schaffer (\)

Philosophy RSSS, Australian National University, Canberra, ACT 0200, Australia

e-mail: jonathan.schaffer@anu.edu.au
} 
$T_{\text {you }}$, one first produces an apt regimentation into, say, first-order classical logic. Letting ' $a$ ' denote you, the natural regimentation is:

$$
T_{\text {you }}^{*}(\exists x) x=a
$$

Now $T^{*}$ you can only be true relative to a domain $D$ which contains $a$. Hence $a$ is needed by the domain for $T^{*}{ }_{\text {you }}$-our apt regimentation of $T_{y o u}$ - to come true. Hence $T_{\text {уои }}$ is ontologically committed to you. Or so the quantifier view rules.

On the rival truthmaker view (Armstrong 2004, pp. 23-24), a theory is committed to what is needed in the world for the theory to be made true. Applied to $T_{\text {you }}$ one is to plug in one's favorite account of truthmaking (more on this to follow: Sect. 2), such as:

TNec: $(\forall p)\left(\forall w_{1}\right)$ (if $p$ is true at $w_{1}$ then $(\exists x)$ ( $x$ exists at $w_{1} \&\left(\forall w_{2}\right)$ (if $x$ exists at $w_{2}$ then $p$ is true at $\left.\left.\left.w_{2}\right)\right)\right)^{1}$

TNec says that for every true proposition there is some entity $x$ whose existence necessitates that truth. Given that you are the one and only entity whose existence necessitates the truth of $<$ you exist $>, T_{\text {you }}$ is ontologically committed to you. Or so the truthmaker view rules.

Advocates of the truthmaker view include Armstrong, Heil, and Cameron. Thus Armstrong holds that "To postulate certain truthmakers for certain truths is to admit those truthmakers to one's ontology. The complete range of truthmakers admitted constitutes a metaphysics..." (2004, p. 23) Heil says "[W]e turn out backs on the idea that ontology can be settled by analysis" speaking of truthmaking as the alternative: "When a claim about the world is true, something about the world makes it true." (2003, p. 9) And Cameron, perhaps most explicitly, writes:

What are the ontological commitments of a theory? For Quine, it is those things that must be said to lie within the domain of the quantifiers if the sentences of the theory are to be true. I am a truthmaker theorist: I hold that the ontological commitments of a theory are just those things that must exist to make true the sentences of that theory. (2008, p. 4; c.f. Cameron and Barnes 2007, p. 26)

The friends of the truthmaker view have offered three main reasons to prefer it to the quantifier view. First, there is the feeling that the quantifier view takes too much of a detour through language. Thus Heil says that if you would "uncover the ontology of statues," you shouldn't ask "whether talk of statues could be analyzed into talk of material out of which statues are made," but rather you should "ask what the truth-makers might be for assertions of the form, 'This is a statue.'" (2003, p. 9) Likewise Cameron warns against "...a wrong-turn: serious ontological questions are being decided by linguistic facts;" (2008, p. 5). For instance: "[W]hether we are committed to complex objects is being decided by whether or not sentences concerning them can be paraphrased away into plural quantification over simples" (forthcoming, p. 5).

\footnotetext{
1 Convention for variables: Here and in what follows, " $p$ " is dedicated to propositions, and " $w$ " (as well as its subscripted counterparts " $w_{1}$ " and " $w_{2}$ ") to worlds.
} 
The second main reason given for preferring the truthmaker view is the idea that the quantifier view builds in biases by construction. Thus Armstrong says:

Why should we desert Quine's procedure for some other method? The great advantage, as I see it, of the search for truthmakers is that it focuses us not merely on the metaphysical implications of the subject terms of propositions but also on their predicates. (2004, p. 23)

The focus on the subject term results from the Quinean preference for first-order logic. If we also maintain the classical association of first-order individuals with objects, then the focus on the subject term yields a nominalistic bias against properties.

Third, there is the idea that the truthmaker view allows for radically minimal ontology without tears. The idea is that one can have as minimal an ontology as mereological nihilism (c.f. van Inwagen 1990), while still endorsing common-sense existence claims. Thus Heil writes: "I am inclined to think that 'this is a statue' can be, and often is, literally true. What makes it true is a complex, dynamic arrangement of particles..." (2003, p. 53). As Cameron explains:

What's wrong, in my opinion, is the Quinean idea that we have to resist the literal truth of 'there are tables' if we want to avoid ontological commitment to tables. This idea blocks what, intuitively, is a very attractive option: that the nihilist is right about the ontology but that the universalist is right about what sentences are true. Once we allow that the truthmaker for $<x$ exists $>$ can be something other than $\mathrm{x}$ this becomes an option on the table: 'there is a sum of A, B and C' might be true-but perhaps we don't need a complex object to make it true: perhaps $\mathrm{A}, \mathrm{B}$ and $\mathrm{C}$ themselves are enough to make this sentence true. (2008, p. 5)

I am unpersuaded by any of these three arguments. As to the first argument that the quantifier view involves "a wrong turn" through language, I see no way around using language in the theory of ontological commitment. Theories themselves are sentences, and what they commit to has to be at least in part a function of what these sentences mean. As to the second argument that the quantifier view is biased against predicates, I am happy to allow higher-order quantification. At least, nothing in the quantifier view per se requires restriction to first-order quantifiers. As to third argument that the truthmaker view allows for radically minimal commitments, I think this is not an attraction but an embarrassment. I think that theories like mereological nihilism are interesting in the way that epistemological skepticism is interesting, the main question for both being how do we avoid this? In this vein, turn to $T_{\text {you }}$. This theory ought to be committed to you existing-surely if any theory can be committed to you existing, $T_{\text {yоu }}$ should do the trick. It is bad if the believer in $T_{\text {you }}$ is allowed to shirk commitment to your existing, but only to be committed to 'a complex, dynamic arrangement of particles' or something of that ilk.

Obviously there is much room for further discussion of all three arguments. My purpose however is not to defend the quantifier view, but rather to assess the truthmaker view. So I leave further discussion of the quantifier view aside, and turn instead to the prospects for a truthmaker view of commitment. 


\section{Truthmaker commitments}

On the truthmaker view of commitment, a theory is committed to the entities needed in the world for the theory to be made true. But there are many views of the truthmaking relation, and thus many truthmaker views of commitment. The question is whether any view of the truthmaking relation can yield a viable measure ontological commitment.

There are three main theories of truthmaking to consider. First, there is the Armstrongian view of truthmaking as necessitation (c.f. Bigelow 1988; Armstrong 1997):

TNec: $(\forall p)\left(\forall w_{1}\right)$ (if $p$ is true at $w_{1}$ then $(\exists x)\left(x\right.$ exists at $w_{1} \&\left(\forall w_{2}\right)$ (if $x$ exists at $w_{2}$ then $p$ is true at $\left.\left.\left.w_{2}\right)\right)\right)^{2}$

On TNec, a truthmaker is an entity whose existence necessitates the truth of the proposition in question. Second, there is the Lewisian view of truthmaking as supervenience (c.f. Lewis 2001; Bricker 2006):

TSup: $\left(\forall w_{1}\right)\left(\forall w_{2}\right)(\forall p)$ (if $p$ is true at $w_{1}$ and false at $w_{2}$, then $w_{1}$ and $w_{2}$ differ in being [either in what there is, or how it is])

On TSup, truthmaking is the claim that no two worlds differ over the truth of a proposition without also differing over either what there is or how it is. Third, there is the view I have advocated elsewhere via grounding (c.f. Schaffer forthcoming):

TGro: $(\forall p)(\forall w)$ (if $p$ is true at $w$, then $p$ 's truth at $w$ is grounded in the fundamental features of $w$ )

On TGro, truthmaking is the claim that the truth of propositions is not a fundamental feature of reality, and as such requires grounding in what is fundamental.

I will now argue that neither TNec, nor TSep, nor TGro can be used to properly measure ontological commitment. Obviously this is not in itself a decisive result, for two reasons. First, for all I will be saying it could still be that the quantifier viewand all other alternatives-fare even worse, so it could still be that the truthmaker view is the best of a very bad lot. Second, for all I will be saying it could still be that there is some fourth yet-to-be-discovered view of truthmaking which will vindicate the truthmaker view of commitment. To this I can only reply, tell me more.

\subsection{Truthmaking as necessitation}

Truthmaking as necessitation- $\mathrm{TNec}-$ is the orthodox view of truthmaking, which Armstrong and Cameron explicitly endorse. It will also turn out to be the only account of truthmaking that has any claim to provide a measure commitment. So I

\footnotetext{
${ }^{2}$ Those sceptical of unrestricted composition may replace ' $(\exists x)^{\prime}$ ' with the plural quantifier ' $(\exists x x)$ ' and speak plurally of 'the truthmakers,' as the entities whose joint existence necessitates the truth of the proposition in question. Those sceptical of transworld identity may replace 'if $x$ exists at $w_{2}$ ' with 'if $x$ has a counterpart at $w_{2}$ ' or (better) 'if $x$ has a duplicate at $w_{2}$.' Nothing in what follows will turn on these details.
} 
begin here. I will first offer some general objections to TNec (which I consider to be an indefensible theory of truthmaking), and then show that-general objections aside- $\mathrm{TNec}$ is in any case not apt for measuring ontological commitment.

\subsubsection{Truthmaking as necessitation: general problems}

I doubt the general adequacy of TNec. What everyone-or at least everyone friendly to truthmaking - starts with is the intuition that truth depends on being. Such an intuition traces back to Aristotle:

[I]f there is a man, the statement whereby we say that there is a man is true, and reciprocally-since if the statement whereby we say that there is a man is true, there is a man. And whereas the true statement is in no way the cause of the actual thing's existence, the actual thing does seem in some way the cause of the statement's being true: it is because the actual thing exists or does not exist that the statement is called true or false. (1984, p. 22)

This intuition echoes in Leibniz's claim that "it is evident that every true predication has some basis in the nature of things,..." (1960, p. 416), and resurfaces in Armstrong's question: "Must there not be something about the world that makes it to be the case, that serves as an ontological ground, for this truth?" (1997, p. 115).

The intuition that truth depends on being, however, ought not yield anything like TNec. Think of other dependency hypotheses, such as the thesis that the mental depends on the physical. The following parallel account is widely regarded as unsustainable:

MNec: $\left(\forall m: m\right.$ is a mental entity) $\left(\forall w_{1}\right)$ (if $m$ exists at $w_{1}$ then $(\exists x)\left(x\right.$ exists at $w_{1}$ $\&\left(\forall w_{2}\right)\left(\right.$ if $x$ exists at $w_{2}$ then $m$ exists at $\left.\left.\left.w_{2}\right)\right)\right)$

On MNec, every mental entity is accorded a 'mind-maker' whose existence necessitates the existence of the mental entity in question (e.g. some particle whose existence necessitates a thought). In the mind-body case it is widely accepted that the dependency is better understood via something like (minimal) supervenience or grounding. ${ }^{3}$ This moral should be applied to the truth-being case.

Some other differences between dependency and necessitation include: (i) dependence is irreflexive and asymmetric, while necessitation is reflexive and nonasymmetric; and (ii) dependence is hyperintensional, but necessitation is intensional. Indeed the whole point of Aristotle's example of truth depending on being was that the truth of the proposition and the existence of the man are intensionally equivalent, yet there is an asymmetry of dependence.

As a result of misrendering the dependency of truth on being, the TNec theorist suffers at least four subsequent misfortunes. First, she falls into trivial truthmaking so long as she recognizes the existence of facts, and in particular the existence of

\footnotetext{
3 Among the many problems with $\mathrm{MNec}$ is the problem that the mind-making physical entity(s) could exist in a dualistic world, where the dualistic addition makes different mental entities exist (c.f. Hawthorne 2002; Leuenberger forthcoming). For instance, let my brain-state $b$ ground my pain-state $m$. Still it is possible that $b$ exist in a dualistic world $w$ where my spirit state $s$ changes things so that $b$ and $s$ together do not yield pain-state $m$. In $w, b$ exists but $m$ does not.
} 
facts of the form ' $p$ is true.' Let $p$ be any true proposition whatsoever. Let $x$ be the fact that $p$ is true. Then $x$ will provide a trivial truthmaker for $p$-at any world where you have the fact that $p$ is true, $p$ must perforce be true. Thus the requirement that all truths have truth-necessitaters is no requirement at all, but an empty formality. The hope of the truthmaker theorist to 'catch the cheaters' (those who posits truths without truthmakers) is squandered with TNec.

Second, the TNec theorist finds wrong truthmakers for necessary truths. For any necessarily true proposition $p$, such as $<2+2=4>$, every single entity (e.g. my left ear, your right foot) counts as a truth-necessitater. After all, in every world in which my left ear exists, $<2+2=4>$ remains true. There are substantive questions of dependency for mathematical and other necessary truths, which TNec collapses.

Intuitively what has gone wrong in these first two objections to TNec is that the necessitation relation in $\mathrm{TNec}$ is not dependency. The reason why the fact that $p$ is true cannot truth-make $p$, is that the fact that $p$ is true just is p's being true. Dependency is an irreflexive relation-nothing is allowed to depend on itself. The reason why my left ear cannot make $<2+2=4>$ true is that the truth of this proposition is not grounded in my left ear. Dependency is a hyperintensional relation-the mere fact that every world where my left ear exists is a world where $<2+2=4>$ is true does not establish dependency.

Third, the TNec theorist discards rightful truthmakers. Suppose that I am contingently sitting. Any theorist who posits the existence of a contingently sitting me seems to be positing reality enough to ground the truth of $<\mathrm{I}$ am sitting $>$ (c.f. Merricks 2007, pp. 21-22). Such a theorist is no cheater. But T-Nec would say otherwise. For given that I am only contingently sitting, my existence does not necessitate the truth of $<\mathrm{I}$ am sitting $>$. In this respect the truthmaker theorist who uses TNec to catch cheaters is in danger of going on a witchhunt.

Fourth, the TNec theorist mishandles negative existentials. Consider the true proposition $<$ there are no dragons $>$. No run-of-the-mill actual entities can truthnecessitate this proposition. Take any such actual entities. All of these can exist in a larger world, which also contains a dragon. So their existence fails to truthnecessitate $<$ there are no dragons $>$. Thus the TNec theorist must invent strange new fundamental entities. For instance, Armstrong (2004, p. 58) posits a fundamental totality fact, which is the negative second-order fact that there are no further factsa posit which offends against both the intuition that the fundamental entities are first-order, and that they are positive in nature. ${ }^{4}$

Intuitively what has gone wrong in these latter two objections to TNec is that the legitimate demand for the fundamental grounds for truths, has been replaced by a

\footnotetext{
${ }^{4}$ Indeed Armstrong's totality fact, insofar as it conjoins all the first-order facts and then says that there are no more, further offends against the intuitions that the fundamental entities ought to be amenable to free recombination, and ought to be non-redundant. As to free recombination, none of the first-order facts can be altered without altering the totality fact, and the totality fact cannot be altered without altering at least some of the first-order facts. As to non-redundancy, the totality fact entails all the first-order facts. Indeed, once one posits the fundamental totality fact, it is mysterious why one would bother to posit any fundamental first-order facts whatsoever, since all of these are already entailed. The totality fact can go it alone.
} 
different demand for entities whose existence necessitates these truths. This leads to a demand for strange new fundamental entities, with rigid essences and negative features.

But enough with general problems for TNec. The hardcore proponent of using TNec to measure ontological commitment could - in principle-drop the claim that TNec furnishes an apt theory of truthmaking, and just offer it up directly as a measure of commitment. So I now turn to three specific problems for $\mathrm{TNec}$ as a measure of commitment.

\subsubsection{Truthmaking as necessitation: everything is lost}

Suppose for the sake of argument that $\mathrm{TNec}$ could provide a viable account of truthmaking. I will now argue that $\mathrm{TNec}$ still cannot provide a viable measure of ontological commitment. My first argument is that truth-necessitation commitment shirks commitments from objects and properties.

The TNec theorist may choose which entities she takes to be the truthnecessitaters. Armstrong takes states-of-affairs to be the right sort of entities for the job. They have wide enough content (having both an object and a property constituent), and fragile enough modal profiles (having their object and property constituents essentially) to serve as truth-necessitaters. But tropes could serve as well, if rendered as (i) essentially belonging to a certain object (non-transferable), and (ii) essentially exactly as they are. Indeed objects could serve as well (in principle), if rendered as being essentially exactly as they are. ${ }^{5}$

I will follow Armstrong in supposing that the truthmakers are states-of-affairs, for the sake of definiteness. So:

1. The truth-necessitaters are states-of-affairs (and thus neither objects nor properties)

But now given the truth-necessitater view of commitment (e.g. Armstrong's claim that ' $[t]$ he complete range of truthmakers admitted constitutes a metaphysics'), we have:

2. A theory is only committed to its truth-necessitaters

From which it immediately follows:

3. Thus a theory is only committed to states-of-affairs (not objects nor properties)

One might think it an open question which objects and properties a given theory is committed to. But on TNec (given 1) the question is closed from the start, and the trivial answer is none at all. One might think that $T_{\text {you }}$ is evidently committed to you. But given TNec, $T_{\text {you }}$ is only committed to states-of-affairs, and I presume that you are not a state-of-affairs.

As a result, truth-necessitation theorists like Armstrong are committed to the following inconsistent triad. Letting $T_{\text {best }}$ be a true and complete theory:

\footnotetext{
${ }^{5}$ Another way to get objects to serve is to modify TNec from 'if $x$ exists at $w_{2}$ ' to 'if $x$ has a duplicate at $w_{2}$.' See Parsons 1999 for further discussion.
} 
4. What is in the ontology are all and only the truth-necessitaters for $T_{\text {true }}$

5. The truth-necessitaters for $T_{\text {true }}$ are all states-of-affairs

6. Object and properties are in the ontology

Indeed, objects and properties are supposed to be the constituents of states-ofaffairs. So one might have thought that objects and properties get into the ontology, so long as the states-of-affairs they are to be abstracted from exist. Not so. For if 'the complete range of truthmakers admitted constitutes a metaphysics,' the constituents are out of the game.

Generalizing away from 1, suppose the truthmakers are tropes. Then:

7. The truth-necessitaters are tropes

8. A theory is only committed to its truth-necessitaters

9. Thus a theory is only committed to tropes (not objects nor facts)

Now the classical trope theorist constructs objects from bundles of tropes, and property types from resemblance classes of tropes. So one might have thought that objects and property types get into the ontology, so long as the tropes they are constructed from exist. Not so. For if 'the complete range of truthmakers admitted constitutes a metaphysics,' the constructions are out.

Further generalization of the argument is left to the reader. But I think there is an obvious moral. What the state-of-affairs theorist wants to say is that states-of-affairs are fundamental, and objects and properties derivative abstractions. What the trope theorist wants to say is that tropes are fundamental, and objects and property types derivative constructions. But she can't say this if she takes the truthmakers to be what a theory says there is; she can only say this if she take the truthmakers to be what a theory says is fundamental.

\subsubsection{Truthmaking as necessitation: the uniqueness problem}

My second argument that TNec cannot provide a viable measure of ontological commitment stems from the fact that TNec does not in general provide unique truthnecessitaters. This will be shown to lead to the following dilemma:

10. If a theory is committed to all of its truth-necessitaters, then there is spurious over-commitment

11. If a theory is only committed to some of its truth-necessitaters, then-at least on the most plausible way of implementing this, involving minimal truthmakers - there is shirking under-commitment

To begin, TNec does not in general guarantee unique truth-necessitaters. Consider the truth $<$ you exist $>$. Suppose for the sake of the argument that the stateof-affairs of you existing is a truth-necessitater for $<$ you exist $>$. Still, it is not the only one. For consider the conjunctive state-of-affairs of you existing and me existing. Any world where this conjunctive state-of-affairs is to be found is a world where <you exist $>$ will be true. In the extreme, consider the massive conjunction of all states-of-affairs. Any world where this massively conjunctive state-of-affairs is to be found is also a world where <you exist $>$ will be true. 
In general, TNec-style truthmaking is closed under expansion. ${ }^{6}$ Thus if $x$ truthnecessitates $p$, then any expansion of $x$ (where conjunction is the appropriate expansive principle for states-of-affairs) will equally truth-necessitate $p$, since the expansion contains the entity $x$ (as a conjunct) whose existence already guarantees the truth of $p$. So any truth that is truth-necessitated by anything less than the massive conjunction of all states-of-affairs will enjoy multiple truth-necessitaters.

Now the trouble begins. Earlier (Sect. 1) I had glossed the truthmaker view as "a theory is committed to the entities needed in the world for the theory to be made true." Likewise Cameron says "the ontological commitments of a theory are just those things that must exist to make true the sentences of that theory" (2008, p. 4) But given the many truth-necessitaters, it is not clear what this means. One should ask the theorist who would measure commitment via TNec, which of the many truth-necessitaters are the commitments?

Suppose the answer is that all the truth-necessitaters are commitments (as per 10). Then there will be spurious overcommitment. Consider again the theory $T_{\text {you }}$, whose only claim is that you exist. As just explained, among the truthmakers of $T_{\text {уо }}$ are the conjunctive state-of-affairs of you existing and me existing, and the massive conjunction of all states-of-affairs. Now if ever a theory was noncommital with respect to anything, $T_{y o u}$ is non-commital with respect to my existence, and with respect, say, to the state-of-affairs of Fido barking. But on the 'all' answer $T_{\text {уои }}$ has wound up committed to me, Fido's barking, and everything else in the entire world!

Suppose then that the answer is that only some of the truth-necessitaters are commitments (as per 11). Then one should ask, which? There is an obvious answer-which should whittle the commitments of $T_{\text {you }}$ down to your existingnamely that the commitments are to the minimal truthmakers. The minimal truthmakers are, according to Armstrong, those from which "you cannot subtract anything... and the remainder still be a truthmaker for $p$ " (2004, pp. 19-20). ${ }^{7}$ Indeed, Armstrong speaks of minimal truthmakers as being "of quite special importance for metaphysics" (2004, p. 19), so perhaps he has something like this idea in mind.

Yet—as Armstrong explicitly points out-there are some truths that have no minimal truthmakers. As a first example, suppose $<$ there are denumerably many electrons $>$ is true. The state-of-affairs $\left[e_{1}\right.$ exists $\& e_{2}$ exists $\& e_{3}$ exists $\&$...] would serve as a truth-necessitater, but so would $\left[e_{2}\right.$ exists $\& e_{4}$ exists $\& e_{6}$ exists $\&$...], and so would $\left[e_{4}\right.$ exists \& $e_{8}$ exists \& $e_{12}$ exists \& ...], ad infinitum (Armstrong 2004 , p. 21; example attributed to Restall). As a second example, suppose that the

\footnotetext{
${ }^{6}$ This is the principle that Smith $(1999$, Sect. 4) refers to as TN+: if $x$ truth-necessitates $p$, the $x+y$ truth-necessitates $p$.

${ }^{7}$ I must confess that I do not fully understand what 'subtraction' comes to for states-of-affairs. These have both object and property constituents. Presumably minimality on the object constituent can be spelled out mereologically, in terms of not being to subtract any parts and still have a truthmaker for the proposition in question. But minimality on the property constituent is trickier. Presumably one should not be able to subtract any conjuncts. But what about determinate-determinable relations? Should we also think of the determinable as 'subtracted' with respect to specificity? Fortunately the argument to come will not turn on any of these questions.
} 
ice cube is gunky (every part of it has proper parts), and that every part of it is homogeneously pink. Consider the truth <something is homogeneously pink $>$. The state-of-affairs of the existence of any part of the ice cube would serve as a truthnecessitater, but so would the state-of-affairs of the existence of any proper part of that part, and so on without limit.

Thus consider the following theory of the number of electrons:

$T_{e}$ : There are denumerably many electrons

Obviously $T_{e}$ is committed to denumerably many electrons. But if the commitments are to the minimal truthmakers, then-since $T_{e}$ has no minimal truthmakers $-T_{e}$ winds up being treated as if it had no commitments whatsoever! Instead of requiring infinitely many things from the world, $T_{e}$ is getting treated as if it required nothing.

Perhaps there is some better version of the 'some' answer that does not require minimal truthmakers. Once again, all I can say is, tell me more.

\subsubsection{Truthmaking as necessitation: quantifier revenge}

My third and final argument that $\mathrm{TNec}$ cannot provide a viable measure of ontological commitment stems from the fact that TNec itself merely offers further existential quantification. This will be shown to lead to the following dilemma:

12. If existential quantification is not generally ontologically committal, then it is mysterious why the specific existential quantification in $\mathrm{TNec}$ is committal

13. If existential quantification is generally ontologically committal, then it is not mysterious why the specific existential quantification in $\mathrm{TNec}$ is committal-it is because the quantifier view is true.

To begin with, suppose that existential quantification is not generally ontologically committal (as per 11). Consider the truth of $<$ you exist $>$. Given TNec, all that follows is an existentially quantified conclusion, to the effect that there exists an entity which truth-necessitates <you exist>. If existential quantification is not generally ontologically committal, what is so special about this one? Why in particular should the existentially quantified claim in the consequent of $\mathrm{TNec}$ be committal, but the simpler existentially quantified claim in the natural regimentation of $<$ you exist $>$ be non-committal? This seems unprincipled.

Suppose instead that existential quantification is generally ontologically committal (as per 11). Then it is no mystery why the existentially quantified conclusion of TNec is committal. It is because the quantifier view is true. But now it emerges that truthmaker commitments are parasitic upon quantifier commitments, and so the truthmaker view cannot possibly replace the quantifier view.

Perhaps there is some way to hold a restricted version of the quantifier view, on which (i) existential quantifications are committal only when they also involve some further feature $R$, and (ii) the existential quantification embedded in the consequent of TNec is the only type of existential quantification to also involve this feature $R$. Pending a plausible candidate for being feature $R$, I can only conclude that truthnecessitater commitments presuppose quantifier commitments. 


\subsection{Truthmaking as supervenience}

This section will be short. While TSup is a partial improvement over TNec with respect to the guiding intuition of truthmaking theorists that truth depends on being, TSup manifestly provides no measure of ontological commitment.

TSup is a partial improvement over TNec insofar as supervenience is somewhat akin to a dependency relation. Yet, as is now widely acknowledged, supervenience differs from dependency in respect of being neither irreflexive nor asymmetric, going vacuous for necessary entities (c.f. McLaughlin and Bennett 2005, Sect. 3.5), and being intensional rather than hyperintensional. At most, supervenience should be thought of as Kim thinks of it, as "suggesting the presence of an interesting dependency relation that might explain it" (1993, p. 167).

As a result of continuing to misrender the dependency of truth on being, the TSup theorist still suffers from the first two of the four general objections leveled against TNec in Sect. 2.1.1. Truth-supervenience goes trivial if there exist facts of the form ' $p$ is true' in the supervenience base. And truth-supervenience cannot distinguish real from bogus bases (e.g. my left ear) for necessary truths.

But never mind all that, for TSup manifestly provides no measure of commitment. TSup makes no claims about what there is. It merely makes a global supervenience claim about worlds. The most TSup will tell you is that-if a given theory $T$ is true at $w_{1}$ and false at $w_{2}$-then $w_{1}$ and $w_{2}$ must differ in being. But TSup says nothing about what that difference might consist in, and nothing specific beyond the claim of difference about what there is at $w_{1}$ or $w_{2}$. If we want the theory $T_{y o u}$ to be committed to your existence-or even to the existence of your particles or something at least relevantly affiliated with you-TSup is no help. ${ }^{8}$

\subsection{Truthmaking as grounding}

This section will be short as well. While I think TGro is the best account of truthmaking-directly implementing the guiding intuition that truth depends on being-TGro does not concern what there is, but only concerns what is fundamental.

TGro directly implements the guiding intuition that truth depends on being (I use the phrases " $x$ depends on $y$ " and " $x$ grounds $y$ " interchangeably). Perhaps this notion of grounding/dependency is further analyzable, and perhaps not. But in any case it cannot be analyzed as necessitation or supervenience. (For this reason TNec and TSup are hopeless as accounts of the dependence of truth on being.) Grounding is an asymmetric, irreflexive, and transitive relation. It thus induces a partial ordering, whose minimal elements are the fundamental entities (the ground of being, that on which all else depends).

\footnotetext{
${ }^{8}$ It may be worth recalling that Lewis himself endorsed the quantifier view of commitment (c.f. Lewis 1999). TSup was simply not built for the task of measuring commitments. This is no objection to TSup per se, but only an objection to the attempt to put TSup to a further task it was never intended for.
} 
There are propositions and they have truth-values. But—adds the TGro theoristsemantic features such as the fact that a proposition is true are not fundamental features of reality. Like all non-fundamental features of reality, they require grounding in what is fundamental. Just as the mental and moral are (arguably) grounded in the physical, so the semantical is grounded in the fundamental.

Thus TGro has the best claim to capture the Leibnizian dictum that "every true predication has some basis in the nature of things,..." (1960, p. 416), and to mesh with the Armstrongian query concerning the "ontological ground" for truth (1997, p. 115). It thereby avoids all four of the objections leveled against TNec in Sect. 2.1.1. Facts of the form ' $p$ is true' are not allowed to be truth-grounders because they are not fundamental. My left ear is not allowed to truth-ground necessary truths because there is no dependency. States-of-affairs with rigid essences are not required to be fundamental. And no fundamental negative or second-order truths need be countenanced. ${ }^{9}$

But never mind the general adequacy of TGro. It is manifestly not concerned with what there is, but rather with what is fundamental. Of course not every entity is a fundamental entity.

\section{Fundamentality commitments}

I have argued that none of the three leading accounts of truthmaking - in terms of necessitation, supervenience, and grounding - can provide a viable measure of ontological commitment. So (pending some new fourth account of truthmaking that might fare better) I must reject the truthmaker view of commitment. I have also suggested that the grounding account of truthmaking does provide a needed constraint on what is fundamental. What is fundamental must be such as to ground the truth of all true propositions. With this in mind I offer a conciliatory conclusion. The truthmaker commitments are not a rival to quantifier commitments, but a needed complement. The quantifier commitments are what a theory says exists, while the truthmaker commitments are what a theory says is fundamental.

The fundamentality commitments of a theory are what the theory says is fundamental. Often enough a theory will have disjunctive fundamentality commitments, which are best viewed as constraints. To illustrate, return to the theory $T_{\text {you }}$. This theory is fundamentality-committed to the existence of fundamental entities sufficient to ground the truth of the proposition that you exist. This does not tell us whether these fundamental entities are an arrangement of particles, or perhaps an effective wave-function abstracted from the wave-function of the whole universe, or anything else. But it does impose constraints. Supposing that particles are fundamental, it tells us that the fundamental entities include particles arranged you-wise.

Once the ontological commitments of a theory are separated from its fundamentality commitments, it emerges that some advocates of the truthmaker

\footnotetext{
${ }^{9}$ See Schaffer (forthcoming) for further defense of TGro. See especially Sect. 4 for an explanation of how to handle negative existentials through the combination of TGro with a monistic view of what is fundamental.
} 
view of ontological commitments may have been implicitly targeting fundamentality commitments all along. Thus consider the following passage from Heil:

I am inclined to think that 'this is a statue' can be, and often is, literally true. What makes it true is a complex, dynamic arrangement of particles... We cannot hope to paraphrase, translate, or replace talk of statues with talk of such collections. Even so, it seems clear that, with few exceptions, objects like statues that populate our everyday surroundings owe their existence to arrangements of more ultimate constituents. (2003: 53-54)

These 'more ultimate constituents' to which objects like statues 'owe their existence' are of course not the statues themselves, but their grounds.

Thus I conclude - in a conciliatory manner-that truthmaker commitments are useful tools. They only need to be re-conceived in terms of truth-grounding, and retargeted to the task of fundamentality commitments.

Acknowledgements Thanks to Ross Cameron, Matti Eklund, and the audience at Ontological Commitment in Sydney.

\section{References}

Aristotle. (1984). Categories. In J. Barnes (Ed.), The complete works of Aristotle: The revised Oxford translation (Vol. 1, pp. 3-24). Princeton: Princeton University Press.

Armstrong, D. M. (1997). A world of states of affairs. Cambridge: Cambridge University Press.

Armstrong, D. M. (2004). Truth and truthmakers. Cambridge: Cambridge University Press.

Bigelow, J. (1988). The reality of numbers: A physicalist's philosophy of mathematics. Oxford: Oxford University Press.

Bricker, P. (2006). The relation between general and particular: Entailment vs supervenience. Oxford Studies in Metaphysics, 2, 251-287.

Cameron, R. (2008). Truthmakers and ontological commitment: Or how to deal with complex objects and mathematical ontology without getting into trouble. Philosophical Studies, 140, 1-18.

Cameron, R., \& Barnes, E. (2007). A critical study of John Heil's 'From an ontological point of view'. SWIF Philosophy of Mind Review, 6, 22-30.

Hawthorne, J. (2002). Blocking definitions of materialism. Philosophical Studies, 110, 103-113.

Heil, J. (2003). From an ontological point of view. Oxford: Oxford University Press.

Kim, J. (1993). Postscripts on supervenience. In Supervenience and mind: Selected philosophical essays (pp. 161-174). Cambridge: Cambridge University Press.

Leibniz, G. W. F. (1960). Discourse on metaphysics. In The Rationalists (pp. 409-453). New York: Anchor Books.

Leuenberger, S. (forthcoming). Ceteris Absentibus Physicalism. Oxford Studies in Metaphysics, 4.

Lewis, D. (1999). Noneism or allism? In Papers in metaphysics and epistemology (pp. 152-163). Cambridge: Cambridge University Press.

Lewis, D. (2001). Truthmaking and difference-making. Nous, 35, 602-615.

McLaughlin, B., \& Bennett, K. (2005). Supervenience. Stanford Encyclopedia of Philosophy. http://setis.library.usyd.edu.au/stanford/entries/supervenience/. Accessed 21 April 2008.

Merricks, T. (2007). Truth and ontology. Oxford: Clarendon Press.

Parsons, J. (1999). There is no 'Truthmaker' argument against nominalism. Australasian Journal of Philosophy, 77, 325-334.

Quine, W. V. O. (1963). On what there is. In from a logical point of view (pp. 1-19). New York: Harper \& Row.

Schaffer, J. (forthcoming). The least discerning and most promiscuous truthmaker. Philosophical Quarterly.

Smith, B. (1999). Truthmaker realism. Australasian Journal of Philosophy, 77, 274-291.

Van Inwagen, P. (1990). Material beings. Ithaca, NY: Cornell University Press. 